ERJ

Engineering Research Journal

Faculty of Engineering

Minoufiya University

\title{
BEHAVIOR OF PILES DURING SOIL CONSOLIDATION
}

\author{
Nagwa Ragab El-sakhawy and Ahmed Abd El_Latief \\ Structural Engineering Department, Faculty of Engineering, \\ Zagazig University, Zagazig, Egypt
}

\begin{abstract}
Piles driven into soft clay are often subjected to downdrag force. The downdrag force develops negative skin friction on the pile shaft. Negative skin friction is the most common problem in the design and construction of pile foundations in soft soil. Depending on the relative movement of the pile soil system, positive and negative skin friction are developed on pile shaft. Neutral plane is defined as the depth at which the relative displacement between the pile and the soil is zero.

This paper presents a study on the behavior of pile during soil consolidation. The experimental work was developed to analyze the negative skin friction and the location of the neutral plane on a single pile embedded in clay. The clay layer was allowed to consolidate. The study concluded that the neutral plane is located toward the end of the pile as the end bearing increases. The depth of neutral plane increases by increasing pile length.

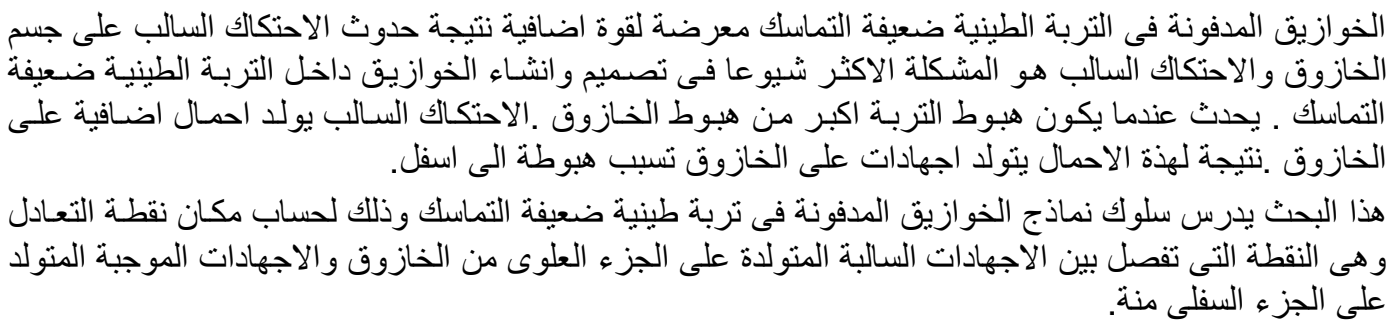

Keywords: Pile foundations, Drag forces, Break forces, Scour, Offshore, Buckling length, Slender ratio, Bending moment, stresses and Bridges
\end{abstract}

\section{INTRODUCTION}

Deep foundations are installed in different soil stratification. Usually penetrated soil stratifications create considerable resistance for the deformation of the deep foundation upon loading. Soil resistance is called shaft resistance or skin friction. This soil behavior can be reversed drastically if the penetrated soil encompasses soft clay.

Soft clay is consolidated upon any slight change in the effective vertical stress. Consolidation causes a downdrag movement to the shaft of the deep pile. The downdrag movement adds additional loads to the already loaded foundation. This force can be expressed as a negative skin friction as it acts in the opposite direction for the normally skin friction.

The negative skin friction will be mobilized in the upper portion starting from the pile head to a neutral depth after which positive skin friction is mobilized in the lower portion. The neutral depth can also be defined as the depth at which the relative displacement between the pile and the soil is zero.

Negative skin friction (N.S.F) occurs when the soil adjacent to the pile settles more than the pile .The settling soil induces additional axial force (drag force) on the pile, causing additional pile settlement (drag down). Down dragloads are introduced by the adhesion between the soil and the pile and to the soil settlement relative to the pile. Increase pile settlement, increase of soil strength will lead to increased downdrag loads on piles due to higher adhesion between pile and soil.

There are five probable, but not limited to reasons for N.S.F:

1- Self weight of unconsolidated recent fill.

2- Surcharge induced consolidation settlement.

3- Consolidation settlement after dissipation of excess pore pressure induced by pile driving.

4- Lowering of ground water table.

5- Compression of soils due to stresses imposed by shallow footing of new adjacent structures (Young and Thorburn, 1981).

\section{EXPERIMENTAL WORK}

In this investigation, experiments on model piles were carried out in order to study the effect of soil consolidation on single pile.

The experimental set up and the equipments used for measurements are described. The test procedures of the experimental work are also outlined.

\subsection{Experimental Rig}




\section{1) Tank}

The experimental rig consists of a circular steel tank with an internal diameter of $300 \mathrm{~mm}$ and a wall thickness of $2 \mathrm{~mm}$. The total height of the tank is $700 \mathrm{~mm}$. The larger pile diameter adopted for this investigation is $2.5 \mathrm{~cm}$. Accordingly to prevent pile interaction with boundaries, researches agreed that pile distance from the boundary should be at least seven its diameter, (Bowels, 1988). The tank diameter was chosen to be $300 \mathrm{~mm}$. Figure 1 shows the experimental rig. A perforated plate of thickness $8 \mathrm{~mm}$ is mounted on four steel rods inside the tank. The steel rods are of length $200 \mathrm{~mm}$ and are rested on the tank base. The perforated plate is $290 \mathrm{~mm}$ outer diameter and $50 \mathrm{~mm}$ inner diameter. The inner hole is designed to allow for free movement of the pile through it. Filter paper is placed between the soil and the plate. Another perforated plate is prepared to settle over the tested soil. The tank is provided with a vent at height $25 \mathrm{~mm}$ from its base. The vent allows for water drainage.

\section{2) The Model Pile}

Three P.V.C circular model piles with different diameters of $1.5,2$ and $2.5 \mathrm{~cm}$ were chosen to model the pile in this study. Compression tests were carried out on a specimen of this P.V.C pipes to determine its modulus of elasticity. The modulus of elasticity of the pile material; P.V.C is $1500000 \mathrm{KN} / \mathrm{m}^{2}$. The surface of the pile is smooth. Pile alignment device was designed to hold the model pile in position through the holes in the lower and upper plates. The pile model was covered at its top by a circular P.V.C plate $3.75 \mathrm{~cm}$ to mount the dial gauge on it.

\section{3) Upper and lower sand layers}

Two layers of sand with depth $5 \mathrm{~cm}$ for each layer. One of these layers placed on the surface of soft soil and the second layer under the soil. Figure 2 shows the sieve analysis for this sand.

\section{4) The Clay Soil}

For research propose, the use of remolded samples is recommended to avoid the erratic formation of natural soil strata, and to work with large number of identical specimens.

Bentonite soil has been adapted for the experimental investigation in this study. Laboratory tests were carried out to determine the different physical and engineering properties of the tested soil.
The physical properties of clay used in tests are as follows:

$$
\begin{array}{ll}
\text { Liquid Limit }(\text { L.L) } & =104 \% \\
\text { Plastic Limit }(\text { P.L) } & =48.6 \% \\
\text { Dry Unit Weight }\left(\gamma_{\text {dry }}\right) & =12 \mathrm{KN} / \mathrm{m}^{3} \\
\text { Plasticity Index }(P . I) & =55.4 \% \\
\text { Consistency Index }(\text { C.I }) & =0.59
\end{array}
$$

\section{Engineering Properties}

The range of published Young's modulus of soft clay is $500-2000 \mathrm{KN} / \mathrm{m}^{2}$ (ECP 202-2002). Several trials with different water content were attempted adapting consolidation tests to locate a bentonite soil within this range of Young's modulus. 85\% water content provides a soft consistency of bentonite. For this condition initial void ratio is 2.38 , bulk density is 16 $\mathrm{KN} / \mathrm{m}^{3}$.

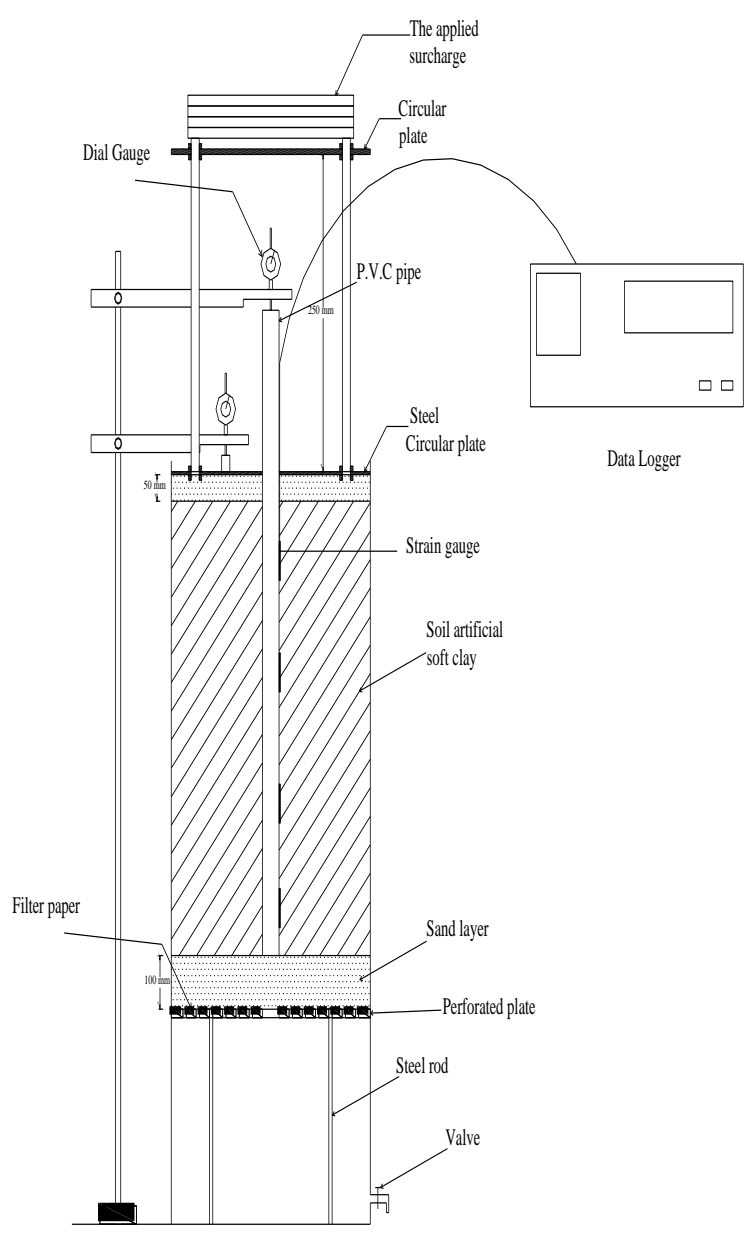

Fig. 1 The experimental rig

\section{Physical properties}




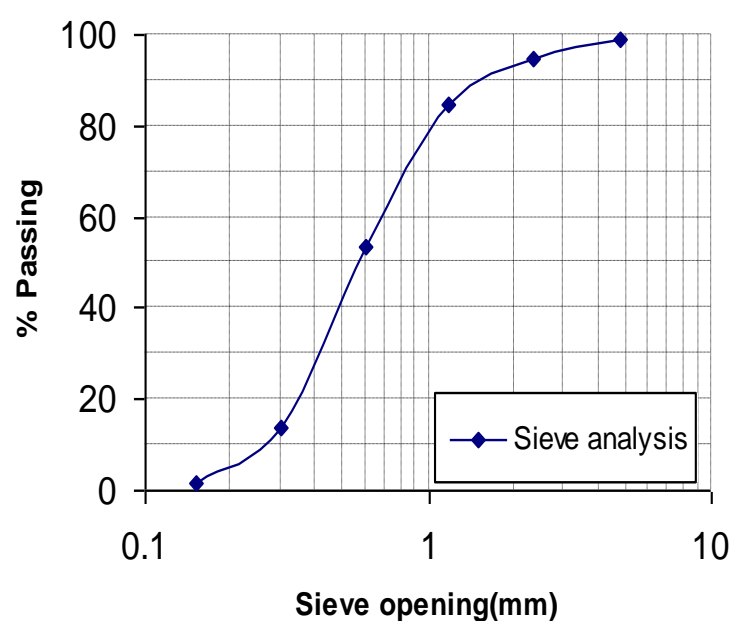

Fig.2 Sieve Analysis test for the upper and lower sand layer

\section{5) Loading System}

A surcharge fill of $1 \mathrm{~m}$ sand is simulated to be applied on the clay layer. Assuming the unit weight of sand is $17 \mathrm{KN} / \mathrm{m} 3$, this gives a surcharge pressure of $17 \mathrm{KN} / \mathrm{m} 2$. In this experimental model, the tank diameter is $30 \mathrm{~cm}$ then the applied load should be 1.2 KN. A surcharge has to be applied to the soil layer for consolidation. The surcharge loads consist of steel and lead plates. These plates are having no center holes of the size of the pile. Also sizes of these plates are larger than the size of the tank. This is why a partial arrangement was prepared to carry the loading outer the boundary of the tank and higher than the top of the piles. As shown in Figure 3, the arrangement consists of two plates; base and upper separated by four steel rods. The rods are $25 \mathrm{~cm}$ length and $1 \mathrm{~cm}$ diameter.

\section{6) Monitoring Devices}

The vertical displacement of the model pile and the soil surface were measured using dial gauges. The accuracy of the dial gauges are $0.01 \mathrm{~mm}$. The holders of the dial gauges were connected to a steel bar with $1 \mathrm{~m}$ height welded to a steel base. The base was rested on the stable ground, as shown in Fig. (1).

The displacement of the model pile is measured at its center. The soil settlement is measured at a point located at the mid distance between the pile shaft and the container wall.

The strain gauges are fixed at various depths of the length of the pile to measure the strains occurred on the pile during soil consolidation. Photo (1) shows the model pile with strain gauges. Number and locations of the strain gauges are designed depending on the thickness of the clay layer.

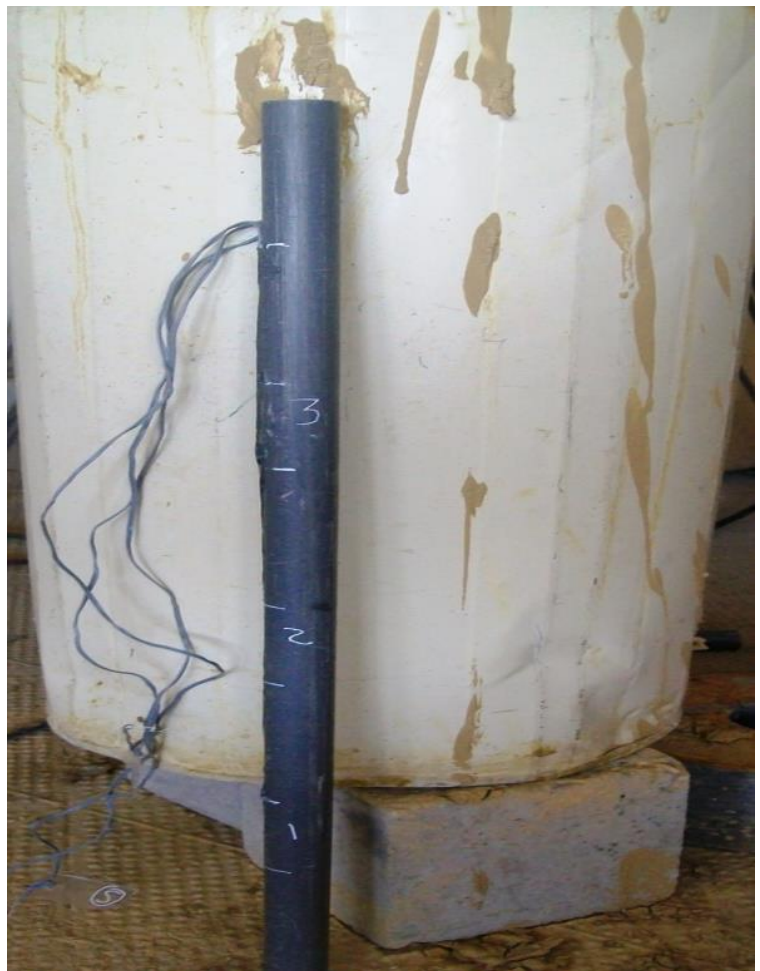

Photo (1): The model pile with strain gauges.

\subsection{The Experimental Setup}

- The model pile is instrumented with strain gauges. The appropriate number and locations of the strain gauges are explained in the next section of experimental program. The pile is lowered vertically and aligned in the tank before the placement of the clay soil.

- $10 \mathrm{~cm}$ of sand layer over the perforated plate. The filter paper was used between the sand layer and perforated plate. Filter paper was aimed to drainage water and keeps the sand.

- Bentonite was used in the testing program to simulate the natural soft clays. According to the designated thickness of the clay layer, an amount of the dry bentonite is weighted. The suitable amount of water is added to the dry soil to obtain a water content of $85 \%$. It was founded by trials that this ratio of water content provides a soft consistency of the bentonite.

- The circular plate is placed over the soil in the container. This plate distributed the pressure from load to the soil uniformly and compresses the layer of soil.

\subsection{The Experimental Program}

Table (1) illustrates the experimental program. 19 tests were carried out to study the behavior of single pile during soil consolidation. Three cases of boundary conditions were considered in this study. The first case is the pile ended in the clay layer. This 
represents clay end bearing case. The second case is the pile ended in the sand layer as shown in Fig. (3) and the last case represents floating pile. That is, the pile passes through the lower plate and not resting on any soil. This case is aimed to investigate the pure shaft resistance without the interference of the end condition.

8 tests were carried out for the first and second case. These tests were divided into three groups according to the pile diameter. The three tested pile diameter are $1.5,2.0$, and $2.5 \mathrm{~cm}$. The ratio of pile length to diameter was considered in this study. They are 10,15 , and 20 . Only pile with diameter $2.5 \mathrm{~cm}$ is considered for the third case. This diameter suits the hole in the perforated lower plate.

Table 1, Different cases with code for each test

\begin{tabular}{|c|c|c|c|c|c|c|}
\hline Test No. & Cases & \begin{tabular}{|c} 
Pile \\
Diameter \\
$(\mathrm{cm})$
\end{tabular} & L/d & $\begin{array}{c}\text { Pile } \\
\text { Length } \\
(\mathrm{cm})\end{array}$ & Code & $\begin{array}{l}\text { No. of } \\
\text { Strain } \\
\text { gages }\end{array}$ \\
\hline 1 & \multirow{8}{*}{ 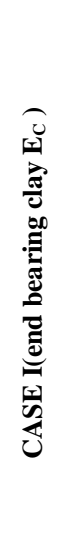 } & \multirow{3}{*}{1.5} & 10 & 15 & $\mathrm{~L}_{15} \mathrm{EC}$ & 3 \\
\hline 2 & & & 15 & 22.5 & $\mathrm{~L}_{22.5} \mathrm{EC}$ & 3 \\
\hline 3 & & & 20 & 30 & $\mathrm{~L}_{30} \mathrm{EC}$ & 4 \\
\hline 4 & & \multirow{3}{*}{2} & 10 & 20 & $\mathrm{~L}_{20} \mathrm{EC}$ & 3 \\
\hline 5 & & & 15 & 30 & $\mathrm{~L}_{30} \mathrm{EC}$ & 4 \\
\hline 6 & & & 20 & 40 & $\mathrm{~L}_{40} \mathrm{E}_{\mathrm{C}}$ & 4 \\
\hline 7 & & \multirow{2}{*}{2.5} & 10 & 25 & $\mathrm{~L}_{25} \mathrm{EC}$ & 4 \\
\hline 8 & & & 15 & 37.5 & $\mathrm{~L}_{37.5} \mathrm{EC}$ & 4 \\
\hline 9 & \multirow{8}{*}{ 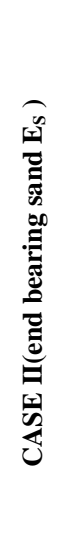 } & \multirow{3}{*}{1.5} & 10 & 15 & $\mathrm{~L}_{15} \mathrm{ES}$ & 3 \\
\hline 10 & & & 15 & 22.5 & $\mathrm{~L}_{22.5} \mathrm{ES}$ & 3 \\
\hline 11 & & & 20 & 30 & $\mathrm{~L}_{30} \mathrm{ES}$ & 4 \\
\hline 12 & & \multirow{3}{*}{2} & 10 & 20 & $\mathrm{~L}_{20} \mathrm{ES}$ & 3 \\
\hline 13 & & & 15 & 30 & $\mathrm{~L}_{30} \mathrm{ES}$ & 4 \\
\hline 14 & & & 20 & 40 & $\mathrm{~L}_{40} \mathrm{ES}$ & 4 \\
\hline 15 & & \multirow{2}{*}{2.5} & 10 & 25 & $\mathrm{~L}_{25} \mathrm{ES}$ & 4 \\
\hline 16 & & & 15 & 37.5 & $\mathrm{~L}_{37.5} \mathrm{ES}$ & 4 \\
\hline 17 & \multirow{3}{*}{ 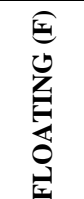 } & \multirow{3}{*}{2.5} & 10 & 25 & $\mathrm{~L}_{25} \mathrm{~F}$ & 4 \\
\hline 18 & & & 15 & 37.5 & $\mathrm{~L}_{37.5} \mathrm{~F}$ & 4 \\
\hline 19 & & & 20 & 50 & $\mathrm{~L}_{50} \mathrm{~F}$ & 4 \\
\hline
\end{tabular}

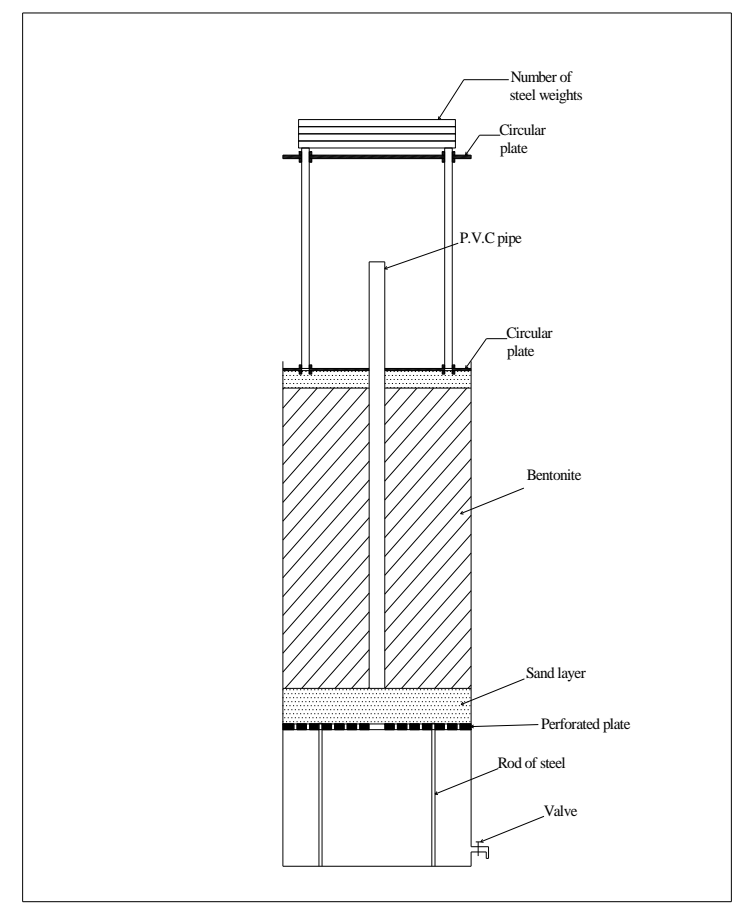

Fig.3 Pile base rest on sand

\section{TIME-STRAIN BEHAVIOR OF PILE MODEL}

When the clay begins to consolidate due to its own weight and the surcharge loads, it exerts a dragdown force. This force acts on the pile model by side friction caused by the increase of the axial strains due to consolidating. The resulting strains on the pile model are measured at various time intervals.

\subsection{Piles ended on clay}

Figures 4 show the axial strain with time of applying the surcharge, for a pile ended in the clay deposit, $1.5 \mathrm{~cm}$ pile diameter and $15 \mathrm{~cm}$ embedded length in clay deposit that is; the pile diameter ratio is 10.

From the figure, it can be seen that the top strain is higher and earlier than the middle and the bottom strains. However, it declines just after reaching the early peak. The others continue increasing the strain until the end of the test.

It is clear that the top portion of the deposit go through consolidation due to the nearby surcharge faster than the remaining deposit. By time, the rate of water dissipation decreases, and, hence, the axial strain decreases.

The middle axial strains continue increasing with lower rate than the initial one. The bottom strain is much less than the upper and middle. The stress increase at the bottom strain is moderate compared with the other two location and hence the water dissipation and the soil consolidation. 


\subsection{Piles ended in sand}

Figure 5 illustrates the pile strains when the piles ended in sand. It is noticeable that the bottom strains are generally larger when compared with the previous case of piles totally ended in clay. This can be attributed to the increased dissipation of pore water pressure through the bottom layer. Moreover, sand layers offer resistance to the pile movement; end bearing. This increases stresses in the bottom portion of the pile. Hence, there is increase in the monitored strain.

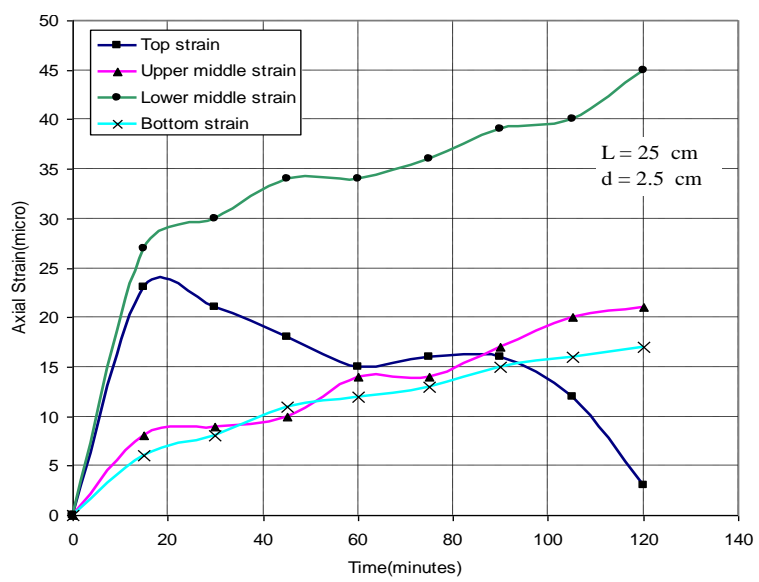

Fig. 4 Time-Axial strain curves of pile model $\left(\mathrm{L}_{25} \mathrm{E}_{\mathrm{c}}\right)$

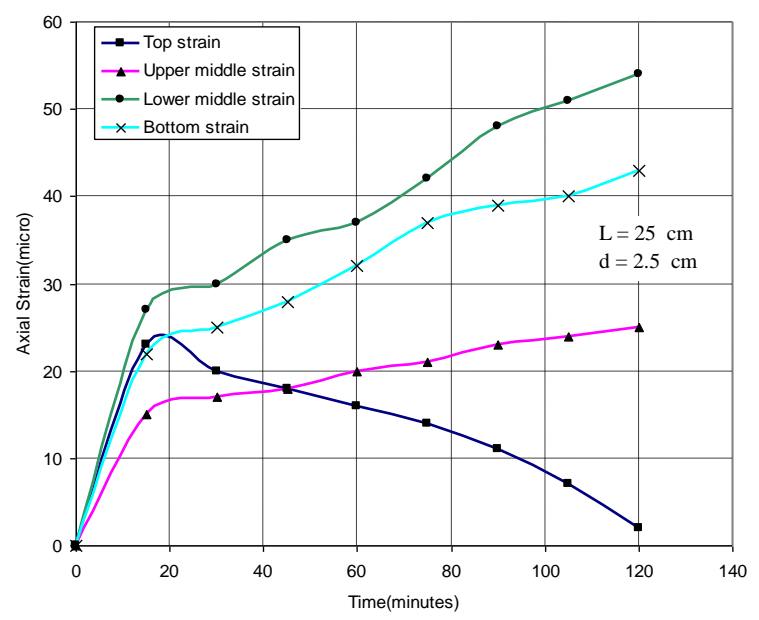

Fig. 5 Time- Axial strain curves of pile model $\left(\mathrm{L}_{25} \mathrm{E}_{\mathrm{S}}\right)$

\subsection{Floated piles in clay}

Figure 6 shows the pile strains when the piles are floated in clay. Here, the boundary condition at the bottom does not allow for developing stresses at the bottom. Hence, the bottom strains are the least among all locations along the pile.

\subsection{Effect of the pile length to the pile diameter} (L/d) on the location of neutral plane

Under surcharge on the soil surface, negative skin friction is induced from the top of the pile and extends progressively downward, until it reaches a maximum value at an intermediate depth. Then, it decreases to a zero value at the level of the neutral plane. Below the neutral plane, positive skin friction develops.

Figure 7 and 8 show the distributions of shear stress with the normalized depth of the clay layer. Neutral plane is determined where shear stress is changing from negative to positive. That is at the intersection of the curve with the vertical axis. Figure 7 shows the location of neutral plane for the case I and II of piles ended in clay and sand, respectively. The pile length is $15 \mathrm{~cm}$. From the figure, it can be seen that the normalized location of the neutral plane is $(0.53)$ and $(0.61)$ for the case of end bearing on clay and sand respectively. That is the neutral plane is located toward the end of the pile as the end bearing increases.

Figure 8 shows Shear stress distribution along pile length for case I and II with pile length $22.5 \mathrm{~cm}$ and diameter $1.5 \mathrm{~cm}$. From the figure, it can be seen that the normalized location of neutral plane for the pile ended in sand is 0.52 . Comparing with the location of neutral plane in the previous figure, it can be seen that the neutral plane has been located further towards the pile tip.

The explanation of the effect of variation of pile length to the pile diameter on the neutral plane is due to the compressibility of the pile length. When negative skin friction is induced in a short pile, most of the downdrag is transmitted to pile tip in form of penetration to the bearing layer. Whereas, for long pile the downdrag is mainly taken by the pile compressibility, and very little is transmitted to the tip. As a result of this mechanism, the neutral plane is located at larger depth in longer piles.

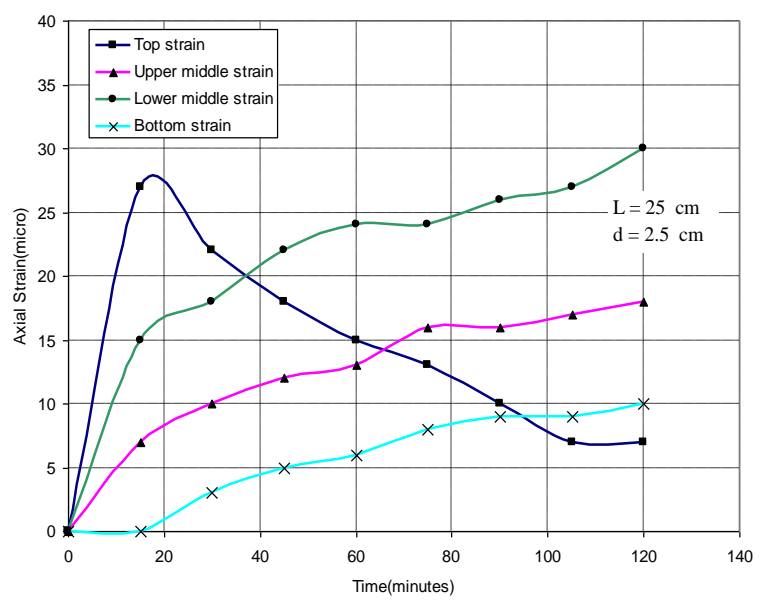

Fig. 6 Time- Axial strain curves of pile model $\left(\mathrm{L}_{25} \mathrm{~F}\right)$ 


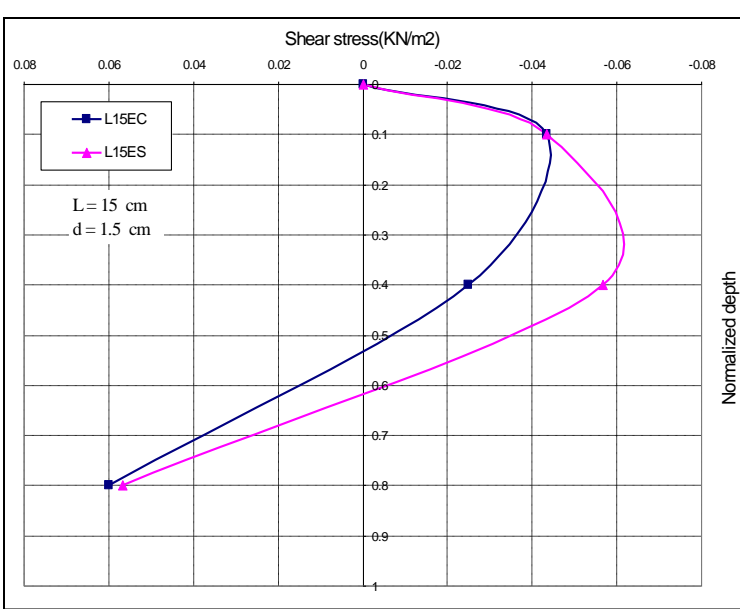

Fig. 7 Shear stress distribution along pile length for cases $\left(\mathrm{L}_{15} \mathrm{EC}\right.$ and $\left.\mathrm{L}_{15} \mathrm{ES}\right)$

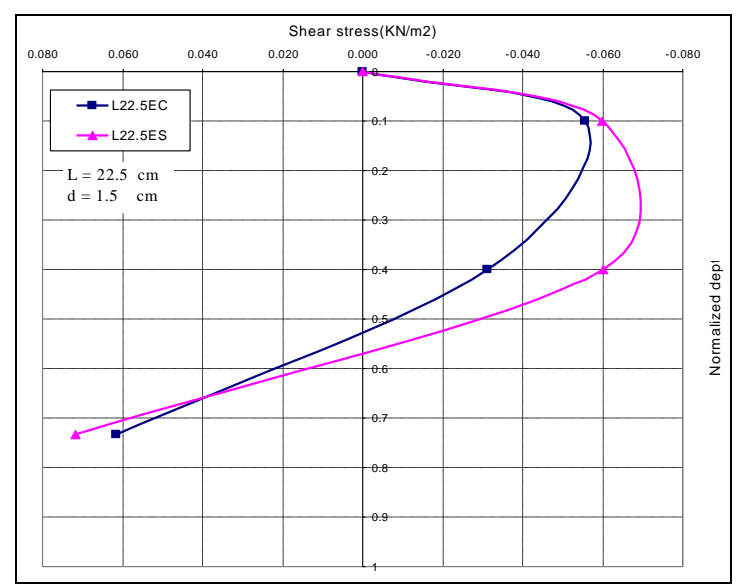

Fig. 8 Shear stress distribution along pile length for cases $\left(\mathrm{L}_{22.5} \mathrm{EC}\right.$ and $\left.\mathrm{L}_{22.5} \mathrm{ES}\right)$

\section{CONCLUSION}

This paper presents a study on the behavior of pile during soil consolidation. The experimental work was developed to analyze the negative skin friction and the location of the neutral plane on a single pile embedded in clay. The clay layer was allowed to consolidate 19 tests were carried out to study the behavior of single pile during soil consolidation. Three cases of boundary conditions were considered in this study. The first case is the pile ended in the clay layer. This represents clay end bearing case. The second case is the pile ended in the sand layer. And the last case represents floating pile. This case is aimed to investigate the pure shaft resistance without the interference of the end condition.

When the clay begins to consolidate due to its own weight and the surcharge loads, it exerts a dragdown force. This force acts on the pile model by side friction caused by the increase of the axial strains due to consolidation. The resulting strains on the pile model are measured at various time intervals.
Time-strain behavior of the pile depends on the soil condition, pile configuration, and depth along the pile.

Based on test results the following conclusions are reached:

1- Under surcharge on the soil surface, negative skin friction is induced from the top of the pile and extends progressively downward, until it reaches a maximum value at an intermediate depth. It the decreases to a zero value at the level of the neutral plane. Below the neutral plane, positive skin friction develops.

2- The neutral plane is located toward the end of the pile as the end bearing increases.

3- The depth of neutral plane increases by increasing pile length.

\section{REFERENCES}

[1] Ali sharif.(1998)," negative skin friction on single piles in clay subjected to direct and indirect loading," M.A.Sc. thesis, Concordia university, Montreal, Quebec, Canda

[2] Bozozuk,M.(1972),"Downdragmeasurements on a 160-Ft floating pipe test pile in marine clay," Can.Geotech. J., Vol. 9, No. 2, PP. 127-136.

[3] Bengt H. Fellenius, Dr. Tech., P.Eng.(2004)," Unified design of piled foundations with emphasis on settlement analysis" ASCE Geotechnical Special Publication, GSP 125, pp. $253-275$.

[4] Bengt H. Fellenius(2006), "Piled Foundation Design - Clarification of a Confusion" Geotechnical News Magazine, Vol.24, No.3 pp.53-55.

[5] Bowles, J. E., "Foundation Analysis and Design” Mc Graw Hill Book Company, 1988.

[6] C.F.Leung, B.K.Liao, Y.K.Chow (2004), "Behavior of pile subject to negative skin friction and axial load," Japanese Geotechnical society, Vol.44, No.6, 17-26.

[7] Endo,M., Minov, A.,Kawaaski, T . and shibata, T. (1969), " Negative skin friction acting on steel pipe-piles in clay,"Proc., 7th. Lint. Conf. SMFE. Mexico, Vol. 2.pp.85-92.

[8] Fellenius, B. H. (1972)," Downdrag on piles in clay due to negative skin friction,"Can. Geotech. j., Vol. 9, No.4, pp. 323-337.

[9] Fellenius, B. H. (1989), "Unified design of piles and pile groups," Transportation Research Record, No. 1169, pp. 75-82.

[10] H. B. Poorooshasb, M. Alamgi \& N. Miura (1996)," Negative Skin Friction on Rigid and Deformable Piles" Computers and Geotechnics, Vol. 18, No. 2, pp. 109-126. 